\title{
RAMIRO CONDARCO MORALES (1927-2009). ESCRITOR POLIFACÉTICO Y CREADOR DEL CONCEPTO DE SIMBIOSIS INTER-ZONAL
}

\author{
Carmen Beatriz Loza ${ }^{1}$
}

Heredero de una notable tradición intelectual, Ramiro Condarco Morales nació en Oruro el 7 de octubre de 1927. Estudió en su ciudad natal y tempranamente sus inquietudes tomaron la forma de un cristal bifronte donde cada cara apuntaba a campos diversos: de un lado la literatura, del otro la antropología y la historia. En Bolivia, donde no existía una academia que canalizase esa vocación, los jóvenes estaban predestinados a estudiar las carreras de medicina o derecho. Don Ramiro -como lo llamábamos respetuosamente quienes fuimos sus estudiantes y compartimos sus intereses y amistadno pudo sustraerse a ese destino, recibiéndose de Licenciado en Derecho, Ciencias Políticas y Sociales en 1952. Poco antes de graduarse se dedicó, entre 1945 y 1948, a intercalar las expediciones en las pampas del altiplano como miembro fundador de la Sociedad Geográfica e Histórica de Oruro. De hecho, antes de esos viajes le sucedieron incursiones hacia los valles de los Departamentos de La Paz y Cochabamba, travesías que le permitieron adentrarse en la dinámica socioeconómica de las sociedades agropastoriles de habla quechua y aymara en las propiedades de sus familiares. Tales experiencias vivenciales se tradujeron posteriormente en la formulación de un concepto nodal: Simbiosis InterZonal en la Economía Andina (Condarco Morales 1971; Carvajal 2005:26-29).

Marcan su vida distintos ritmos signados por los avatares, pero sobre todo por la persistencia, continuidad y linealidad en la dedicación completa a la escritura y publicación con su propio capital, debido a la ausencia de respaldo, inexistencia de institucionalidad y abandono estatal. En 1952, inaugura una larga carrera en la docencia cuyo fruto fue el fortalecimiento de las ciencias sociales, geológicas e históricas bolivianas. Se dedicó, junto a otros, a la creación de la primera carrera de historia en la Universidad Mayor de San Andrés (1972), donde instituyó y ejerció la cátedra de prehistoria (desde
1972 hasta 1987). En la misma carrera propuso, posteriormente, cambios estructurales en el currículo académico que no siempre fueron comprendidos, lo que lo indujo, en un acto de sabiduría y lucidez, a retirarse de este ámbito. A partir de esa experiencia, en los años ochenta, planeó la creación de las carreras de arqueología y antropología en un país donde eran inexistentes, en claro contraste con lo que sucedía en las naciones vecinas ( $c f$. América Indígena 1980). Don Ramiro sentía la urgencia de formar profesionales en esos campos de la ciencia donde se advertía una nítida dependencia de los investigadores extranjeros y por ello se lanzó a la hazaña de fundar la carrera de antropología en la Universidad Técnica de Oruro y la Universidad Mayor de San Andrés de La Paz. La constancia de su preocupación por la educación puede ser entendida como un vestigio del influjo familiar, esta vez de sus entrañables hermanas, Albertina y Laura, también consagradas a la enseñanza. La influencia de ambas fue decisiva en su quehacer escritural al concebir una pequeña empresa editora familiar para difundir su obra polifacética.

Un examen rápido de las obras, señaladas en la bibliografía adjunta, basta para advertir al trabajador infatigable que recorrió, por nosotros y antes que nosotros, el camino que lo apartó del oportunismo en el conocimiento y la carrera académica; ello se revela en la caracterización temprana realizada por sus críticos quienes lo califican de "investigador responsable" (Salamanca 1966:4) y de "honesto buceador de la historia" (Arancibia Herrera 1974); un personaje "excéntrico, raro" y, finalmente, "El científico del siglo XX" en Bolivia. Muchos de sus colegas lo percibieron como retraído por los prolongados períodos en que se mantuvo al margen de la vida intelectual y social, dejando escasos fragmentos de convivencia como miembro de número de las Academias Boliviana de la Lengua, de la Historia y de la Academia Nacional de Ciencias, tal cual 
se infiere de los testimonios acopiados. Este dato resulta clave, pues manifiesta el comportamiento de un hombre que se recogía en sí mismo y ahondaba en examinarse a sí, fiel a la antigua noción de epimeleia heautou. Vale decir, fiel a un ejercicio que consiste en someterse a la punzada de una suerte de agujón plantado ahí, en la carne de los hombres, que corresponde -parafraseando a Michel Foucaulta exhibirse en la existencia porque se trata de un principio de agitación, un principio de movimiento y un principio permanente de la vida.

Su producción bibliográfica garantiza una actividad escritural sostenida. Publicó 20 libros, dejó 10 textos inéditos y centenares de artículos dispersos en la prensa, pero limitados artículos científicos debido a que en Bolivia muchas de las principales revistas -como Khana, Pumapunku o Pukara-eran órganos que privilegiaban la filiación política partidaria de los autores. Aquellos libros que están dedicados a la poesía, este género predilecto ha punteado su vida, pues la poesía es "una actividad que trabaja con el lenguaje, como otras trabajan con los acontecimientos" (Antezana 1986:20). El primer libro de poesía, Cantar del Trópico y la Pampa, es editado en 1948; en esta fecha asimismo publicó otro poemario, Mares de Duna y Ventisquero. Luego de veintisiete años de espera emergió la novela de ficción Zedar de los Espacios (1975); finalmente hacia 1989, Madre Alba y Poemas Lineales. Más un Bouquet de Luz para Yulena.

Aun cuando se advierte una recurrencia intermitente a la poesía, la mayoría de sus libros se adscriben a la historia, la antropología y arqueología y han hallado diversa acogida en el medio boliviano y americanista. Debutó en el campo de la historia con una obra que hoy constituye un clásico de los movimientos indígenas de liberación en los Andes: Zárate: El "Temible Willka". Historia de la Rebelión Indígena de 1899. La primera edición de este libro se produjo en 1966 -cuando no se había institucionalizado la enseñanza de la historia como disciplina- siendo evaluada como una obra que aborda una temática absolutamente subestimada por la historiografía boliviana de la época (Salamanca 1966:4). Conforme a lo manifestado por el literato boliviano Carlos Castañón Barrientos se trata de "uno de los libros más extraordinarios" de los últimos tiempos por su rigor, el manejo de fuentes y el trabajo de campo. Aprovecho para recordar que, respecto a la repercusión de la aludida obra en el extranjero, ésta se hace sentir dieciocho años después, cuando fue invitado a dictar un ciclo de conferencias en la Universidad de Heidelberg acerca de los levantamientos indígenas bolivianos de los siglos XIX y XX (Duchén Condarco 2009:35-64). Esta problemática acicatearía a otros investigadores a centrarse en ella, ahondando en su estudio ( $c f$. Fundación del Banco Central, Museo de Etnografía y Folclore, Archivo de La Paz 2007).

En el contexto de un país periférico, Don Ramiro se animó a escribir y editar un libro de carácter teórico denominado El Escenario Andino y el Hombre. Ecología y Antropología de los Andes Centrales que se publicó en La Paz en 1971. Allí plantea cuidadosa y extensamente su modelo de simbiosis inter-zonal en la economía andina. Un año después de la aparición del libro de Don Ramiro, en el seno de una prestigiosa Universidad Hermilio Valdizan, el etnólogo rumano-estadounidense John V. Murra (1916-2006) acuña el concepto de "control vertical de pisos ecológicos" (Murra 1975) al exponer el modelo con evidencia etnohistórica. Los planteamientos de ambos autores, Condarco y Murra, son presentados conjuntamente en La teoría de la complementariedad vertical eco-simbiótica (1987), pero lo que es más importante de esa publicación es el reconocimiento público de Murra acerca del planteamiento original de Condarco. Tal gesto se entiende porque en 1983 fue Condarco quien salió en defensa de Murra cuando se publicaron en el periódico Presencia (La Paz) numerosas críticas y ataques planteados por el arqueólogo boliviano Carlos Ponce Sanginés, quien era contrario al modelo de la simbiosis interzonal (Loza 2009:128-132).

Los planteamientos de Murra sobre la economía andina coinciden en varios y decisivos puntos con otros formulados por Don Ramiro, pero los de este último no recibieron similar crédito y receptividad en la comunidad académica, lo cual se explicaría como efecto geopolítico epistemológico del lugar de enunciación. A ello se agrega algo no menos determinante: la movilización, desde el norte, de redes académicas que publicitan al "control vertical" como la primera y única propuesta, dándose a la tarea de reproducir y acrecentar la clásica asimetría existente, respecto a la producción de conocimiento, entre el centro y la periferia. Mirando en perspectiva, se percibe bien que el éxito de la propuesta del modelo vertical se debe a la actividad minuciosa emprendida por el propio Murra para manejar mecanismos de circulación de su hipótesis en varios continentes a través de sus frecuentes viajes a Europa y Sudamérica 
que facilitaron a sus planteamientos espacios de circulación a gran escala. En efecto, se "ha reconocido que John Murra ha caminado -literalmente caminado- todos los países sembrando sin reposo sus ideas y cosechando discípulos a lo largo de su ruta" (Lorandi et al. 2003:12; véase el Homenaje a Murra en Chungara Revista de Antropología Chilena 42; <www.chungara.cl>). Utilizar esos mecanismos de circulación del conocimiento en la dinámica de validación de la producción científica en el espacio global era inconcebible en la Bolivia de los años setenta, donde primaba la adscripción partidaria del intelectual en un sistema universitario precario. En ese contexto Condarco Morales no pudo contrarrestar la avalancha de información sobre el "control vertical" y difundir su propuesta globalmente, pues apenas contaba con su red familiar y de amistades encargados de difundir sus libros. En todo caso, gracias a la presentación realizada en la revista boliviana Avances. Revista Boliviana de Estudios Históricos y Sociales relativa a esta propuesta clave de Condarco Morales sobre la simbiosis inter-zonal en la economía andina, se ha desarrollado en el país una conciencia acerca de la efectividad de emplear dicho concepto. Al mismo tiempo, Avances colaboró a publicitar en el medio americanista de la época, aunque limitadamente, la existencia de una propuesta planteada desde la periferia en forma paralela a la de Murra. En diciembre de 1978 viajó invitado a Estados Unidos de Norteamérica, más precisamente a Stanford University, a dictar un ciclo de conferencias sobre la "Estructura Política del Imperio Incaico", donde pudo exponer planteamientos que había madurado en una publicación ocho años antes. Aunque se minimizó el aporte desde la academia boliviana más conservadora sobre la simbiosis inter-zonal, recibió a lo largo de su vida numerosas e importantes distinciones bolivianas que dan cuenta, en alguna medida, del reconocimiento que el país le ha prodigado.

Ramiro Condarco Morales, fallecido el 15 de julio de 2009, nos ha legado una conciencia sobre el valor de la investigación histórica y antropológica pensada y practicada desde la periferia. Producir desde una ética rigurosa y una disciplina tenaz es la mejor herencia y, también, la mejor promesa de continuar transitando por las huellas dejadas en cada una de las interrogaciones, en cada una de las nociones propuestas, en cada uno de los poemas nacidos del gesto recurrente de volcar la mirada sobre sí mismo.

\section{Referencias Citadas}

Antezana J., L.H.

1986 Ensayos y Lecturas. Ediciones Altiplano, La Paz.

Arancibia Herrera, M.

1974 Ramiro Condarco y sus escritos. Presencia Literaria

(La Paz), domingo 6 de octubre de 1966.

Castañón Barrientos, $\mathrm{C}$.

1968 Prosa y verso en Bolivia. Presencia Literaria (La Paz), domingo 12 de mayo de 1968, La Paz.

Carvajal, R.

2005 Ramiro Condarco, John V. Murra, y Zárate el temible Willka. Revista Cultural de la Fundación Cultural del Banco Central de Bolivia 3:26-29.

Condarco Morales, R.

1948a Cantar del Trópico y la Pampa. Imprenta López, Buenos Aires.

1948b Mares de Duna y Ventisquero, Romances de Leyenda. Don Bosco, La Paz [recibió el premio de poesía 1948].

1966 [1965] Zárate: El “Temible Willka”. Historia de la Rebelión Indígena de 1899 [Colofón1966], Talleres Gráficos Bolivianos, La Paz.

1967 Protohistoria Andina: Propedéutica. Edición de la Universidad Técnica de Oruro, Oruro.

1968 Atlas Histórico de América. Ediciones Condarco, La Paz.
1970 Primeros años de la vida de Moreno. Pukara 1 (1/2):170188. La Paz.

1971 a Grandeza y Soledad de Moreno. Esbozo Bio-bibliográfico del Príncipe de las Letras Bolivianas. Talleres Gráficos Bolivianos, La Paz.

1971b El Escenario Andino y el Hombre. Ecología y Antropología de los Andes Centrales. La Paz [terminado de imprimir en 1971, premio ensayo 1968].

1971c Rigoberto Paredes: Historiador y Etnógrafo. Edición Isla, La Paz.

1975 Zedar de los Espacios. Litografías e Imprentas Unidas, La Paz.

1976 Lisandro Condarco: investigador pionero. Revista Universidad 2:32-40. Oruro.

1977 Orígenes de la Nación Boliviana: Interpretación Histórico Sociológica de la Fundación de la República. Instituto Boliviano de Cultura, La Paz [premio Presidente de la República 1975].

1978 Reflexiones acerca del eco-sistema vertical andino. Avances. Revista de Ciencias Sociales 1:65-74. La Paz.

1980a Comparación entre Toynbee y Tamayo. Anales de la Academia Boliviana de la Historia 1973-1979, 30-47. La Paz.

1980b América Indígena. Instituto Indigenista Interamericano (México), XL (2):217-224. 
1981a La revolución del pan. En Hoy (La Paz) (Cuadernos de Hoy) 1 (1) 2-5:2.

1981b Estructura política del imperio de los Incas. 43-63. La Revolución del Pan (en Bolivia). La Siglo Ltda., La Paz.

1981c Jesús Lara (1898-1980) como etno-historiador y culturólogo. Historia Boliviana 1-2:101-112. Cochabamba.

1981d Historia de la Ciencia en Bolivia. Historia del Saber Científico en Bolivia/Galardonado con el Primer Premio convocado por la Academia Nacional de Ciencia en Bolivia, en febrero de 1978. Academia Nacional de Ciencias de Bolivia, La Paz.

1983 Zárate: "El Temible Willka”. Historia de la Rebelión Indígena de 1899. Segunda edición revisada con los resultados de nuevas investigaciones y esclarecimientos. Imprenta y Librería Renovación, La Paz.

1985a Aniceto Arce. Artífice de la Extensión de la Revolución Industrial en Bolivia y Forjador de la República. Amerindia, La Paz.

1985b Atlas Histórico de Bolivia. Editorial e Imprenta "San José", La Paz.

1986 Atlas Histórico de América. Con 32 mapas históricos. Segunda edición aumentada de Ramiro Condarco Morales. Talleres Gráficos Bolivianos, La Paz.

1987 En coautoría con John Murra La Teoría de la Complementariedad Vertical Eco-simbiótica. XXX, Hisbol, La Paz (breve Biblioteca de Bolsillo). Ramiro Condarco "Simbiosis interzonal", pp. 7-28.

1988 Grandeza y Soledad de Moreno. Segunda edición. El Mundo, Santa Cruz.

1989 Breve Diccionario de Insultos y Denuestos Castellanos Usualmente Empleados por los Escritores Bolivianos. Ramiro Condarco Morales, La Paz.

1989 Brevísimo Diccionario Filosófico del Buen Humor. 31 p., Editorial e Imprenta “San José”, La Paz.

1989 Franz Tamayo. El Pensador. Editorial e Imprenta "San José”, La Paz.

1989 Madre Alba y poemas lineales. Más un bouquet de luz para Yulena. Editorial e Imprenta "San José”, La Paz.

1989 Tetragramas de la Lengua Castellana. Don Bosco, La Paz.

1989-1990 Temas de Antropología y Arqueología. Editorial e Imprenta "San José", La Paz.

1993 Historia del Ilustre Colegio de Abogados de La Paz. Editorial e Imprenta "San José”, La Paz.

1995 Astronomía y calendario. En La Enigmática Etnoastronomía Andina. La Cruz Escalonada Andina. Primer Encuentro de Cosmovisión Andina "La Cruz Cruzada", pp. 403-450. Centro de Cultura, Arquitectura y Arte Taipinquiri, La Paz.
1998 Etimología de Tiwanaku. Signo. Cuadernos Bolivianos de Cultura 50:189-200. La Paz.

2002a Aniceto Arce. Artífice de la extensión de la Revolución Industrial en Bolivia. Segunda Edición. Fondo Editorial de los Diputados, La Paz.

2002b La mente abarcadora de Alcide d'Orbigny. En El Naturalista Francés Alcide d'Orbigny en la Visión de los Bolivianos, selección, prólogo y notas René Arze Aguirre, pp. 317-326. IFEA, Lima / La Paz.

2002c Condarco Sierra, Lisandro (1886-1894), 580. Diccionario Histórico de Bolivia (redactado bajo la dirección de Josep M. Barnadas con la colaboración de Guillermo Calvo y Juan Ticlla). Grupo de Estudios Históricos, Sucre.

2002d Altiplano. 101 En Diccionario Histórico de Bolivia (redactado bajo la dirección de Josep M. Barnadas con la colaboración de Guillermo Calvo y Juan Ticlla). Grupo de Estudios Históricos, Sucre.

2002e E. Villamil de Rada. 1150-1151. En Diccionario Histórico de Bolivia (redactado bajo la dirección de Josep M. Barnadas con la colaboración de Guillermo Calvo y Juan Ticlla). Grupo de Estudios Históricos, Sucre.

2002f Revolución de 1898-1899. 734-735. En Diccionario Histórico de Bolivia (redactado bajo la dirección de Josep M. Barnadas con la colaboración de G. Calvo y J. Ticlla). Grupo de Estudios Históricos, Sucre.

Duchén Condarco, $\mathrm{R}$.

2009 Ramiro Condarco. Aproximación en la segunda mitad del siglo XX. En Homenaje al Escritor Forjado en los Mares de Tierra. Ramiro Condarco, editado por C. B. Loza y E. Aillón Soria, pp. 35-64. Universidad Mayor de "San Andrés", Carrera de Historia, Facultad de Humanidades, Producciones Cima, La Paz.

Fundación del Banco Central, Museo de Etnografía y Folclore y Archivo de La Paz

2007 Homenaje a Ramiro Condarco. Primera Parte. En torno a la obra de Zárate Willca /Rossana Barragán, DVD, 49 min.

Loza, C.B.

2009 Ramiro Condarco Morales (1927-2009). Productor de conocimiento entre centro-periferia. En Homenaje al Escritor Forjado en los Mares de Tierra. Ramiro Condarco, editado por C.B. Loza y E. Aillón Soria, pp. 117-153. Universidad Mayor de "San Andrés", Carrera de Historia, Facultad de Humanidades, Producciones Cima, La Paz.

Lorandi, A.M., C. Salazar-Soler y N. Wachtel

2003 Los Andes: Cincuenta Años Después (1953-2003). Homenaje a John V. Murra. Fondo de la Pontificia Universidad Católica del Perú, Lima.

Salamanca, R.

1966 Bibliografía. En El Diario, LXIII, N² 21.193, domingo 22 de mayo de 1966:4. La Paz. 


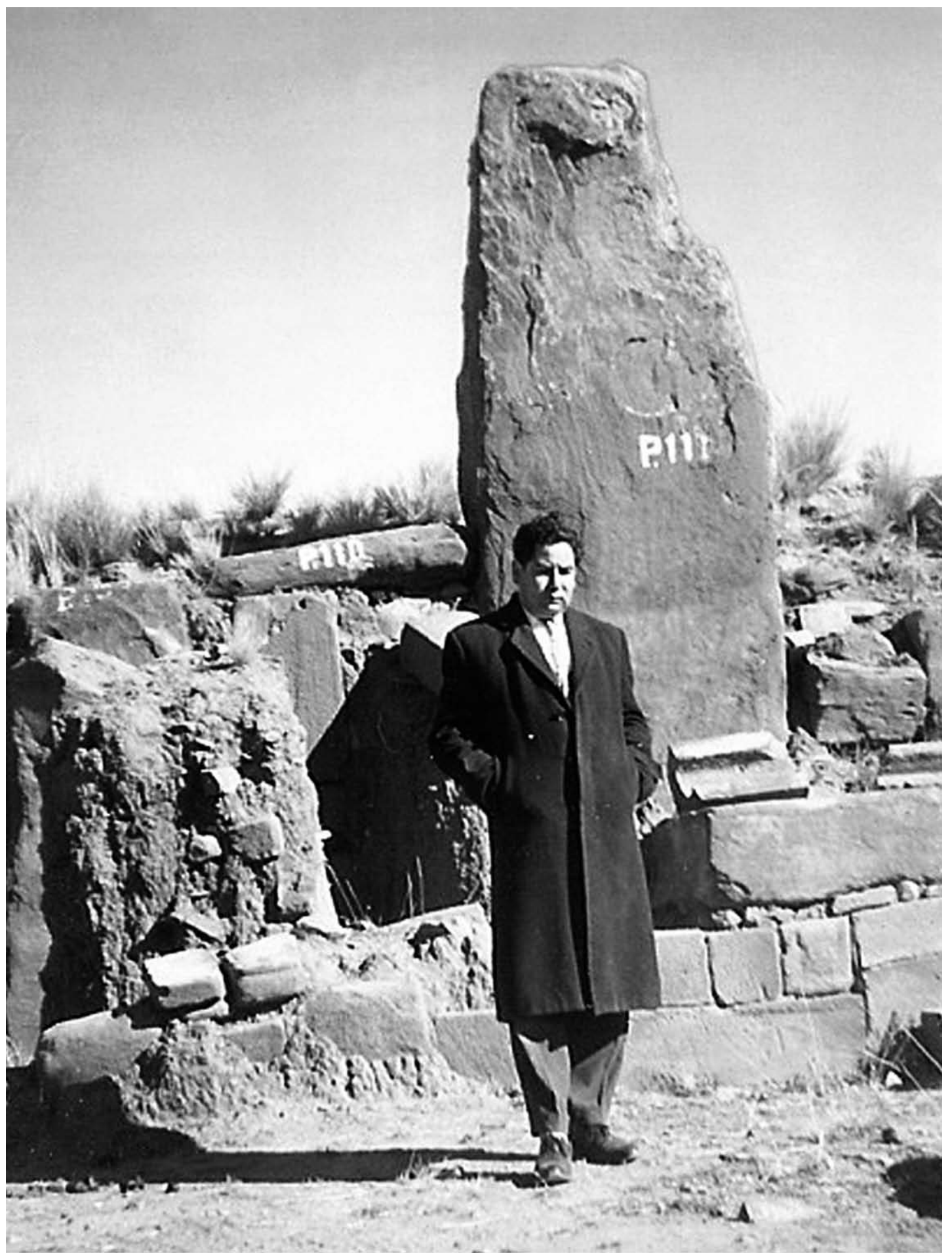

Ramiro Condarco Morales explorando Tiwanaku inmediatamente después de las excavaciones de 1957. Fuente: Archivo familiar de Ramiro Duchén Condarco. 
